Article

\title{
Climatology Characteristics of Ionospheric Irregularities Described with GNSS ROTI
}

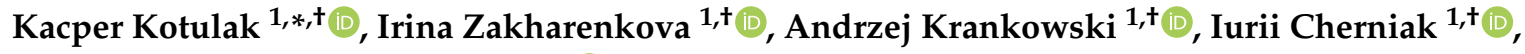 \\ Ningbo Wang ${ }^{2,+}$ and Adam Fron ${ }^{1,+}(\mathbb{D}$ \\ 1 Space Radio-Diagnostics Research Centre, University of Warmia and Mazury in Olsztyn, \\ Oczapowski St. 2, 10-719 Olsztyn, Poland; irina.zakharenkova@uwm.edu.pl (I.Z.); \\ kand@uwm.edu.pl (A.K.); iurii.cherniak@uwm.edu.pl (I.C.); adam.fron@uwm.edu.pl (A.F.) \\ 2 Aerospace Information Research Institute (AIR), Chinese Academy of Sciences (CAS), No 9 Dengzhuang \\ South Road, Beijing 100094, China; wangningbo@aoe.ac.cn \\ * Correspondence: kacper.kotulak@uwm.edu.pl \\ + These authors contributed equally to this work.
}

Received: 30 June 2020; Accepted: 12 August 2020; Published: 14 August 2020

check for updates

\begin{abstract}
At equatorial and high latitudes, the intense ionospheric irregularities and plasma density gradients can seriously affect the performances of radio communication and satellite-based navigation systems; that represents a challenging topic for the scientific and engineering communities and operational use of communication and navigation services. The GNSS-based ROTI (rate of TEC index) is one of the most widely used indices to monitor the occurrence and intensity of ionospheric irregularities. In this paper, we examined the long-term performance of the ROTI in terms of finding the climatological characteristics of TEC fluctuations. We considered the different scale temporal signatures and checked the general sensitivity to the solar and geomagnetic activity. We retrieved and analyzed long-term time-series of ROTI values for two chains of GNSS stations located in European and North-American regions. This analysis covers three full years of the 24th solar cycle, which represent different levels of solar activity and include periods of intense geomagnetic storms. The ionospheric irregularities' geographical distribution, as derived from ROTI, shows a reasonable consistency to be found within the poleward/equatorward boundaries of the auroral oval specified by empirical models. During magnetic midnight and quiet-time conditions, the equatorward boundary of the ROTI-derived ionospheric irregularity zone was observed at $65-70^{\circ}$ of north magnetic latitude, while for local noon conditions this boundary was more poleward at 75-85 magnetic latitude. The ionospheric irregularities of low-to-moderate intensity were found to occur within the auroral oval at all levels of geomagnetic activity and seasons. At moderate and high levels of solar activity, the intensities of ionospheric irregularities are larger during local winter conditions than for the local summer and polar day conditions. We found that ROTI displays a selective latitudinal sensitivity to the auroral electrojet activity-the strongest dependence (correlation $\mathrm{R}>0.6-0.8$ ) was observed within a narrow latitudinal range of $55-70^{\circ} \mathrm{N}$ magnetic latitude, which corresponded to a band of the largest ROTI values within the auroral oval zone expanded equatorward during geomagnetic disturbances.
\end{abstract}

Keywords: ionosphere; ionospheric irregularities; auroral oval; ROTI

\section{Introduction}

Apart from its primary operational objective, the Global Navigation Satellite System (GNSS) has become one of the most important tools in ionospheric research. The greatest advantages over traditional techniques (such as radar/ionosonde and in situ plasma density measurements) are the 
global coverage and continuous, permanent availability [1-4]. Though GNSS signal frequencies have been chosen within the ionospheric disturbances resistant L-band, steeply and rapidly moving plasma density gradients may cause scintillations of the signals phase and intensity $[5,6]$.

The problem of ionospheric plasma density irregularities is very complex, as it depends on a whole range of drivers-from the typical diurnal and seasonal ionization variation to the space weather induced events. Plasma density irregularities in auroral and subauroral latitudes are mainly caused by the auroral particle precipitation and high-speed plasma convection $[7,8]$. The scale of the processes-and thus the irregularities—can be substantially enlarged during geomagnetic storms and substorms $[9,10]$.

Several ionospheric fluctuations models have already been developed [11,12]; however, most of them focus on weak scintillations in the radio signals. Strong ionospheric irregularities may cause serious signal degradation and harmfully impact precise positioning [13]. Satellite navigation is based on the observations from satellites located in various parts of the sky above the receiver-a proper geometry can provide a higher accuracy [14]. Strong scintillations of the received satellite signals may cause the loss-of-lock and in the worst scenarios affect the overall constellation geometry observed, resulting in a serious degradation of performance or full loss of navigation. Thus, development of the ionospheric fluctuations models is crucial for the GNSS users sector as well.

Additionally, many scientific users are interested in the information about the ionosphere rapid dynamics. Nowadays many facilities for radio astronomy operate on low radio frequencies (below $1 \mathrm{GHz}$ and down to even ionospheric critical plasma frequency). Rapid changes in ionospheric plasma density can significantly affect the performances of such instruments as the Low Frequency Array (LOFAR)—a European radio interferometer operating on a frequency range of 20-240 MHz [15]. Such sensitive instruments as LOFAR provide, also, some possibilities of ionospheric irregularity observations [16].

One of the most commonly used scintillation indices is S4, which directly describes fluctuation-caused variations in the signal amplitude; however, it requires dedicated GNSS receivers. It is possible to obtain phase fluctuations using data from standard geodetic GNSS receivers in various worldwide permanent networks. One of the phase fluctuation measures is the rate of total electron content changes index (ROTI). ROTI is proven to have a direct correlation with radio wave scintillations [17]. Another data product describing phase fluctuation activity using GNSS ROTI measurements is being developed, and since 2018 it has been freely accessible as an International GNSS Service (IGS) ROTI map product $[18,19]$. For many years, ROTI has been successfully utilized for ionospheric irregularity studies at sub-auroral [3,20-22] and equatorial [23-27] latitudes. Most often, a detailed ROTI analysis is performed for particular events or case-studies, such as severe geomagnetic storms. In this work, however, we aimed to study extensively the long-term climatology of the ROTI behavior during different periods and conditions. We found some ROTI characteristics during quiet time; disturbed geomagnetic conditions signatures; and solar activity, seasonal, and diurnal dependencies. Better understanding of the ROTI climatological performance would be an important step towards better modeling of the TEC fluctuations' occurrence.

In this paper, we present a long-term analysis of ionospheric irregularities based on GNSS ROTI observations to evaluate ROTI capabilities and find the climatological characteristics for the morphology and variability of the ionospheric plasma density irregularity phenomenon at middle and high latitudes depending on diurnal and seasonal cycles, and on geomagnetic activity.

\section{Materials and Methods}

Today, one of the most commonly-used GNSS-based parameters characterizing the ionospheric plasma density is the total electron content (TEC). In its most basic form (denoted as slant TEC-STEC), it describes the total quantity of free electrons in the ionosphere along the satellite-receiver's line-of-sight (LOS): 


$$
S T E C=\int n_{e}(s) d s
$$

where $n_{e}$ stands for the number of electrons and $s$ for the path of signal along the LoS. TEC is described in TEC units, denoted as TECU, and equal to $10^{16} \mathrm{el} * \mathrm{~m}^{-2}$.

STEC integrates contributions from all electrons along the LOS through the whole ionospheric layer. There are several approaches describing the TEC distribution within the ionospheric layer. The most common, also used in this study, uses the thin single-layer model, which accumulates the TEC value to a single point (ionospheric pierce point-IPP) on a sphere of unit width fixed to a certain altitude representing the whole layer. In this work, we use $350 \mathrm{~km}$ altitude of the ionospheric layer, and an approximation of the free electron maximum density height.

With dual-frequency GNSS receivers, the relative STEC can be directly estimated using a geometry-free combination of GNSS observables [28,29]:

$$
S T E C_{i}=\left(\frac{L 1}{f_{1}}-\frac{L 2}{f_{2}}\right) * \frac{f_{1}^{2} * f_{2}^{2}}{f_{1}^{2}-f_{2}^{2}} * \frac{c}{K}
$$

where $L 1$ and $L 2$ are carrier phase observations performed on frequencies $f 1$ and $f 2$ for the GPS equal $f 1=1525.42 \mathrm{MHz}$ and $f 2=1227.60 \mathrm{MHz} ; c$ is the speed of light in the vacuum; and $K$ is a constant factor equal to 40.3 .

Ionospheric irregularities could be described by the fluctuations of the GNSS signals corresponding to the rapid changes in TEC. Rate of TEC described by $\mathrm{Pi}$ [1] is a simple time derivative of the TEC calculated along the single, continuous GNSS satellite passing arc:

$$
R O T=\frac{T E C_{i+1}-T E C_{i}}{t_{i+1}-t_{i}}
$$

ROT is then a difference of observed nominal slant TEC values in the interval equal to the chosen time unit equal to one minute. ROT is measured in TECU/min. ROT denotes directly the fluctuations of the signal caused by the ionospheric structures. ROT index (ROTI) calculated as a standard deviation of nominal ROT values (Equation (4)) can be used to describe the occurrence of irregularities in the ionospheric plasma density.

$$
R O T I=\sqrt{\left\langle R O T^{2}\right\rangle-\langle R O T\rangle^{2}}
$$

In this study, we calculated ROTI using a running window for 5-min sets of ROT observations. Then, we calculated hourly and daily average ROTI values within cells of 2 degrees in latitude and 2 degrees in longitude-although the daily averages smooth out some peaks in ROTI values, they can be still treated as reasonable measures of the general irregularity occurrence, as the ROTI median value depends on the observation sampling rate rather than the calculation interval [30]. During calculations, we also split the obtained daily values into local day-time and nighttime averages, with day set as 6:00 a.m.-6:00 p.m. local time (LT) and night as 6:00 p.m.-6:00 a.m. LT. To avoid the multipath effect distortion on the ROTI values, we applied a 30 degree elevation angle cutoff mask.

We collected the raw RINEX (receiver independent exchange system) data with a standard 30-s resolution from GNSS permanent stations distributed along two selected meridians, namely, $15^{\circ} \mathrm{E}$ and $100^{\circ} \mathrm{W}$, to illustrate the ionospheric irregularity occurrence in two zones: Europe and North America. Selected chains of GNSS stations belonging to the EUREF Permanent Network (EPN), Continuously Operating Reference Stations (CORS), and Natural Resources Canada (NRCan) properly cover the latitudinal range between $\sim 30^{\circ} \mathrm{N}$ and $\sim 80^{\circ} \mathrm{N}$ (Figure 1). The collected dataset includes observations over three selected years: 2013, 2015, and 2017, representing high, moderate, and low solar activity periods, respectively. Figure 2 shows the monthly averaged sunspot number for the whole 24th solar cycle and three selected time intervals. Such an approach allows one to analyze different time scales and different aspects - the diurnal, seasonal, and annual variations of the ionospheric fluctuations, 
and to examine relationships between geomagnetic activity and latitudinal extent of the auroral irregularity occurrence.

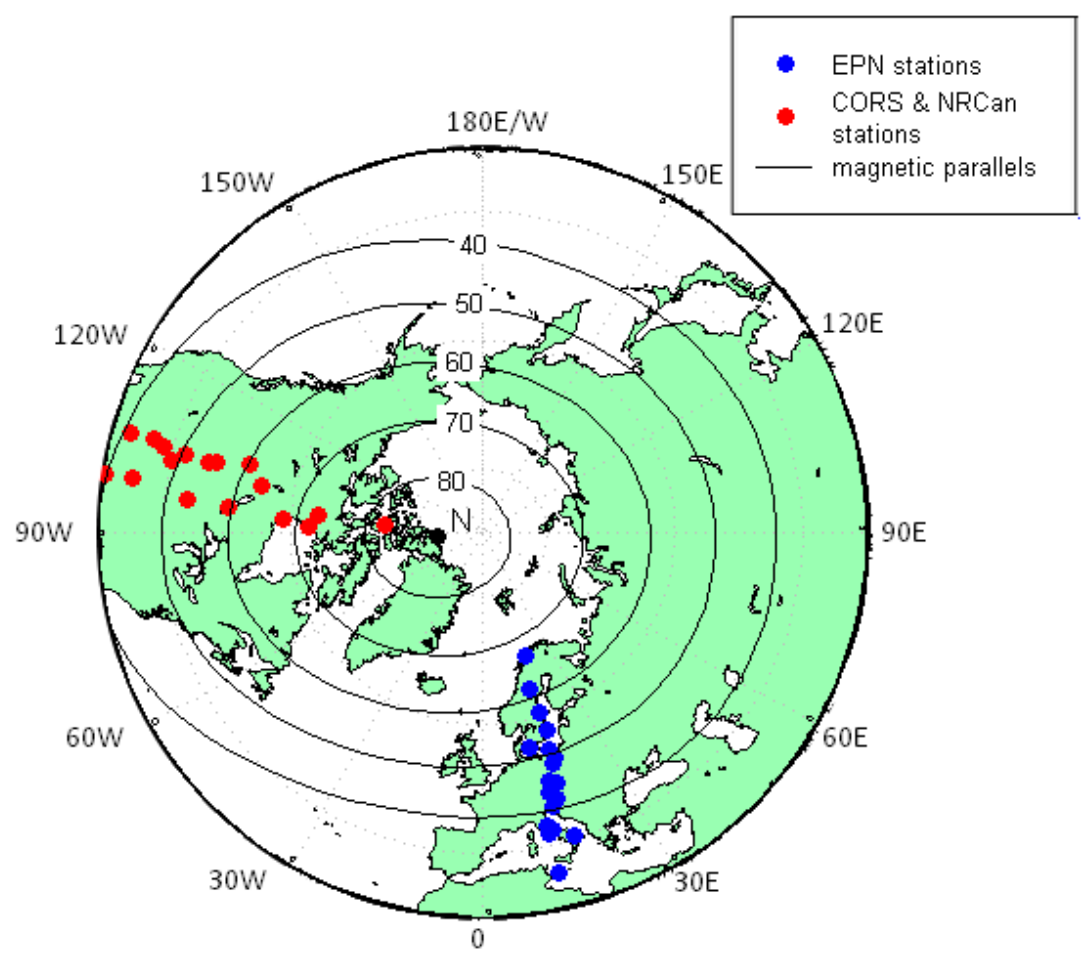

Figure 1. Polar view map with locations of the selected GNSS stations (color dots) in the European and North-American sectors. Thin black lines show the geomagnetic latitude isolines.

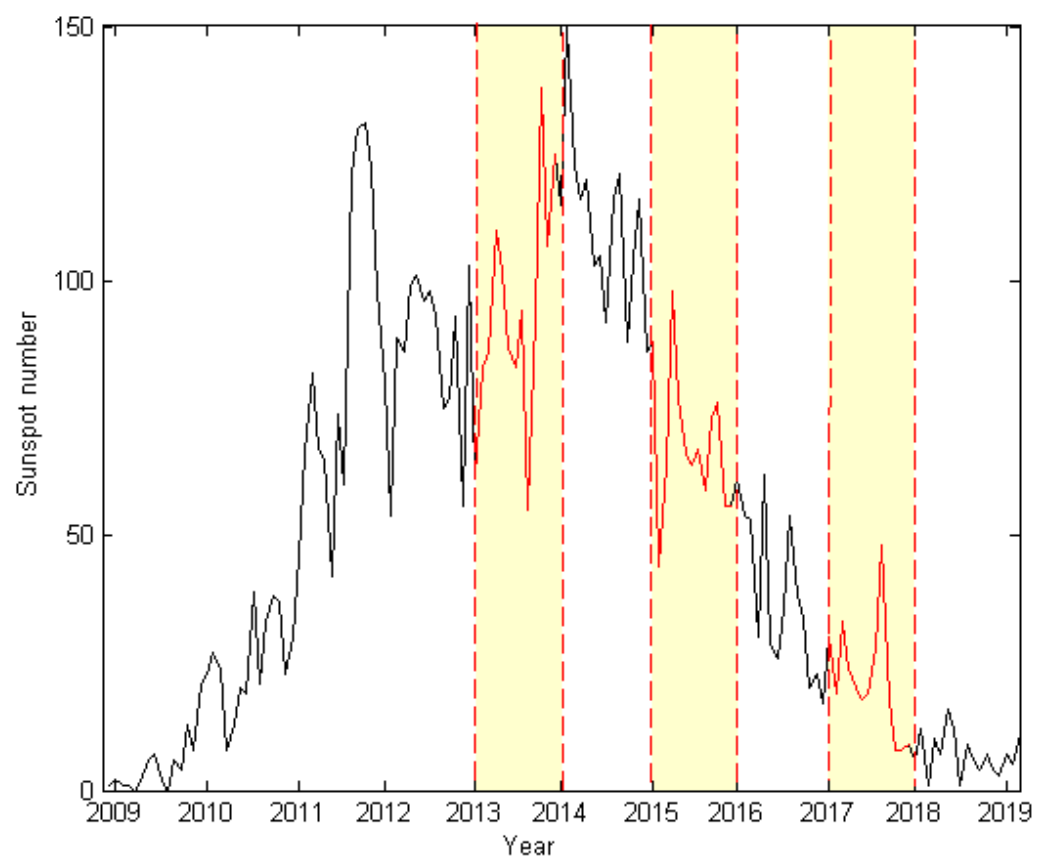

Figure 2. The sunspot number (monthly averaged) in the 24th solar cycle. The highlighted areas show three selected time intervals (years 2013, 2015, and 2017).

Results for 2013, 2015, and 2017 were selected from the whole 11-year dataset, as the most representatives to analyze the solar activity's impact on the ROTI performance-selected years cover 
ascending and descending phases of the solar activity and first part of the solar cycle maximum at the turn of 2013 and 2014. During the above-mentioned periods there also occurred several severe geomagnetic storms. High latitude ROTI—especially in the long scales-reveals sensitivity to the solar conditions. In Figure 3 there is a three-year daily ROTI time-series (for the $65^{\circ} \mathrm{N}$ of magnetic latitude) compared with the daily average sunspot number and F10.7 index.

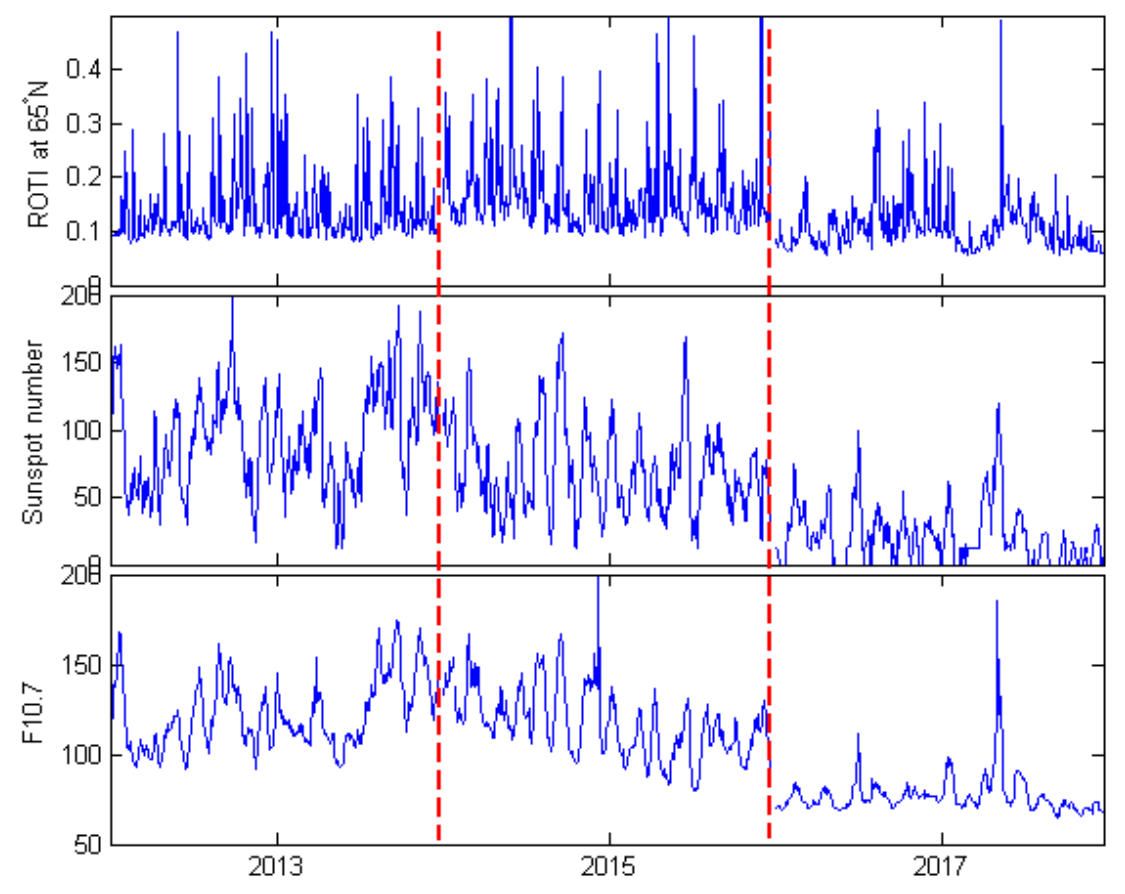

Figure 3. Average high-latitude ROTI comparison with the solar indices (sunspot number R and F10.7 flux).

Although not every peak value in solar indices has a direct counterpart in the high-latitude ROTI values, Figure 3 clearly shows that during low solar activity (2017) the ROTI values are generally lower.

As we assessed the ROTI performance to describe ionospheric irregularity occurrences for various magnetic local time conditions, we converted geographic positions (GLAT, GLON) of the selected stations to magnetic coordinates (MLat, MLon). We also superimposed magnetic isolines in the station map in Figure 1. Sets of geographic and geomagnetic coordinates are shown in Table 1 for the European sector and Table 2 for the North-American one.

After collecting a set of RINEX observation files, we calculated ROTI series for each station with the following steps:

1. We examined the quality of the RINEX files, data gaps, and a number of cycle slips.

2. We calculated ROT values using Equation (3) (taking STEC values for the epoch $t_{i}$ and $t_{i-2}$, as we used standard 30-s RINEX files), taking the 30-degree cutoff mask for the elevation angle.

3. We calculated ROTI values using a 5-min running window with the checking of the observation arc continuity assessment-for each epoch $t$ we included into the calculation ROT values from the previous $5 \mathrm{~min}$, while taking the possibility of observing lags into account as well.

4. We calculated 5-min ROTI average values within 2 degree by 2 degree cells above each station

5. We calculated hourly, day-time, and nighttime LT average ROTI values.

Finally, the derived year-long ROTI series of ROTI values for each year and each station were reorganized into keogram-like time series as a function of time and latitude, with subsequent days of 
the year on the horizontal axis, latitude on the vertical axis, and the corresponding ROTI values from 0 up to 1 on the TECU/min color scale.

Table 1. Geographic and geomagnetic positions of the considered European stations (in degrees).

\begin{tabular}{ccccc}
\hline Station ID & GLAT & GLON & MLAT & MLon \\
\hline TRO1 & 69.663 & 18.940 & 67.115 & 102.790 \\
VIL0 & 64.698 & 16.560 & 62.069 & 97.596 \\
MAR6 & 60.595 & 17.259 & 57.623 & 96.175 \\
VIS0 & 57.654 & 18.367 & 54.343 & 95.952 \\
BUDP & 55.739 & 12.500 & 52.326 & 90.331 \\
REDZ & 54.472 & 17.118 & 50.768 & 93.853 \\
BYDG & 53.135 & 17.994 & 49.209 & 94.214 \\
BOR1 & 52.277 & 17.073 & 48.223 & 93.182 \\
GOPE & 49.914 & 14.786 & 45.424 & 90.588 \\
TUBO & 49.206 & 16.593 & 44.579 & 91.996 \\
LINZ & 48.310 & 14.283 & 43.466 & 89.771 \\
GRAZ & 47.067 & 15.493 & 41.961 & 90.560 \\
GSR1 & 46.048 & 14.544 & 40.681 & 89.508 \\
UNPG & 43.119 & 12.356 & 36.849 & 87.015 \\
AQUI & 42.368 & 13.350 & 35.923 & 87.770 \\
M0SE & 41.893 & 12.493 & 35.249 & 86.923 \\
MATE & 40.649 & 16.704 & 33.898 & 90.510 \\
LAMP & 35.500 & 12.606 & 26.469 & 86.179 \\
\hline
\end{tabular}

Table 2. Geographic and geomagnetic positions of the considered North-American stations (in degrees).

\begin{tabular}{ccccc}
\hline Station ID & GLAT & GLON & MLat & MLon \\
\hline RESO & 74.691 & -94.894 & 82.570 & 326.490 \\
BAKE & 64.318 & -96.002 & 72.630 & 330.740 \\
TKTO & 62.490 & -103.282 & 70.110 & 319.920 \\
ENNA & 60.767 & -101.696 & 68.610 & 320.130 \\
CHUR & 58.759 & -94.089 & 67.340 & 331.150 \\
FLIN & 54.726 & -101.978 & 62.660 & 322.600 \\
SASK & 52.196 & -106.398 & 59.710 & 318.140 \\
DUBO & 50.259 & -95.866 & 58.790 & 331.460 \\
P055 & 47.117 & -104.685 & 54.890 & 321.700 \\
P054 & 45.846 & -104.441 & 53.660 & 322.300 \\
ECSD & 43.734 & -96.614 & 52.260 & 331.880 \\
P042 & 42.052 & -104.911 & 49.860 & 322.610 \\
P044 & 40.172 & -103.222 & 48.160 & 324.900 \\
P037 & 38.422 & -105.105 & 46.250 & 323.090 \\
P123 & 36.635 & -105.911 & 44.400 & 322.510 \\
WMOK & 34.738 & -98.781 & 43.160 & 330.760 \\
P027 & 32.802 & -105.804 & 40.610 & 323.250 \\
P807 & 30.495 & -98.822 & 38.940 & 331.250 \\
\hline
\end{tabular}

In order to evaluate relationships of ionospheric irregularities detected by GNSS ROTI with geomagnetic conditions, we also analyzed the corresponding time series of the AE index-a measure of global electrojet activity based on the measurements from observatories located in the auroral area [31]; and the Ap index denoting the disturbances in the Earth's magnetic field on a global scale, which can also be treated as the auroral oval spread measure. Indices were turned into hourly and daily averages.

Currently there exist few models of the auroral oval ionosphere and the ROTI product could be their reasonable supplement. Additionally, the International Reference Ionosphere (IRI)—although it does not include ionospheric irregularities in any form - had an auroral oval model implemented [32].

To assess the latitudinal distribution of the enhanced ROTI-described irregularities we included the Zhang and Paxton auroral oval model [33] for comparison. This model-included a few years 
ago into the most recent version of the IRI model [34] — is based on the observations performed by the Global Ultraviolet Imager (GUVI) settled on the Thermosphere Ionosphere Mesosphere Energetics and Dynamics (TIMED) mission spacecraft. The GUVI-based model is completely independent from the GNSS-based model and products.

\section{Results}

In terms of GNSS ROTI analysis, the ionospheric irregularity phenomenon can be characterized in several ways. The first one is to analyze long-term time-series of ROTI values; the other one is to analyze the equatorward move of the auroral ionospheric irregularity zone.

For a more clear presentation, the ROTI series are organized in the form of keogram-like color plots, where ROTI is presented as a function of magnetic latitude and time. Figure 4 shows an example of this projection. Here, time-series of GNSS ROTI values calculated for every station of the latitudinal chain are binned into small cells in magnetic latitude, and U.T.; a color of each cell represents an average intensity of ROTI (blue depicts low intensity, while yellow-to-dark red colors show a high level of ionospheric irregularity intensity).

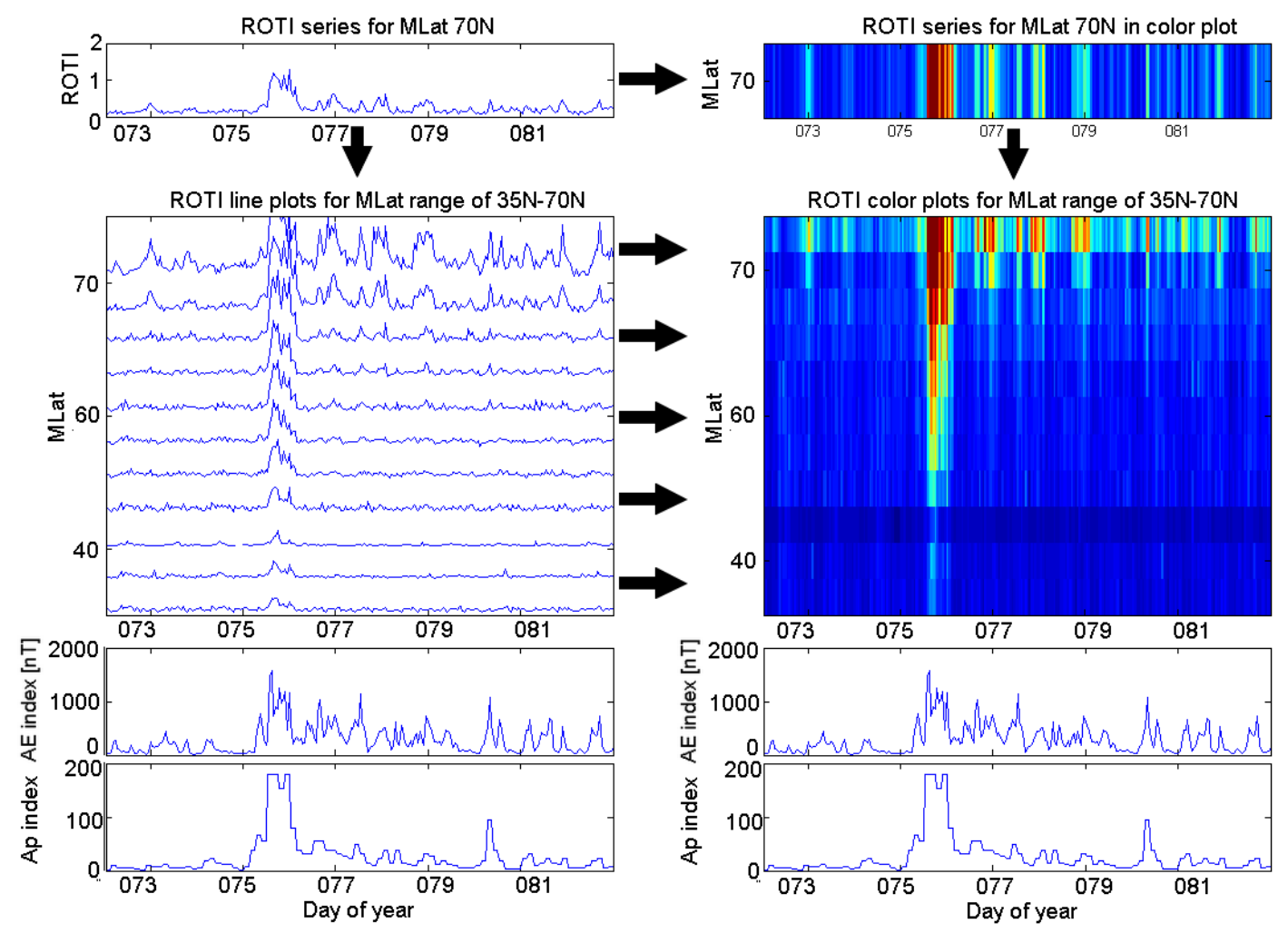

Figure 4. An example for ROTI series reorganization into a keogram-like color plot set together with corresponding Ap and AE values. Days 72-83 of 2015.

Previous studies of ROTI behavior at high latitudes [18,19] reported that ionospheric irregularity occurrence signatures, as derived from ground-based GNSS measurements, have a high degree of similarity with the auroral oval location and they can be discussed in terms of general auroral oval dynamics. Considering diurnal ROTI changes at high latitudes and auroral oval dynamics, one can note a clear difference between ROTI intensity during magnetic daytime and nighttime conditions, both in quiet and disturbed ones. To demonstrate the presence of these signatures in long-term series, we split our ROTI results into daytime and nighttime parts in terms of LT. 
In the study, we selected the European and North-American latitudinal chains of stations-this allowed us to analyze cross sections of the ionospheric irregularities oval at quite opposite longitudinal sectors. Additionally, the North-American network provides a better covering range towards the north magnetic pole, whereas the European stations have a denser coverage of the magnetic latitudes between $50^{\circ} \mathrm{N}$ and $70^{\circ} \mathrm{N}$.

Figures 5-7 present the results of the averaged GNSS ROTI variability together with time-series of the AE and Ap indices for years of 2013, 2015, and 2017, respectively. Each of those figures is organized in the following way-the top two panels present ROTI nighttime and daytime time-series for each latitude in the American sector. Two middle panels present the ROTI time-series constructed for the European chain of stations. The last two panels contain time-series of the AE and Ap indices. Such a presentation provides an easy comparison of ROTI behavior in different zones on the background of various geomagnetic activities.

At high latitudes, large magnitudes of GNSS ROTI values are typically associated with the auroral zone of the intense ionospheric irregularities and gradients, forming the so-called "auroral oval" [35]. The auroral oval is expected to form a ring structure surrounding the magnetic pole [36]. Each ROTI time series in Figures 5-7 presents a latitudinal slice of the auroral oval, as performed on local day-and night-sides in the European and North-American regions.

The color scale is arranged in the following way to determine the occurrence of the significant ROTI values: The minimal value of ROTI that should be considered as "noticeable" is $0.4 \mathrm{TECU} / \mathrm{min}$. Values below this level are marked with blue and correspond to the state of absence or very weak fluctuation activity. ROTI values above $0.4 \mathrm{TECU} / \mathrm{min}$ are marked with light green and move to yellow, then orange, and up to red along with the intensity of the fluctuations. Red corresponds to the ROTI level of 0.9-1.0 TECU/min and above-strong fluctuations that are more typical for intense geomagnetic storms. Such presentation makes it clear to distinguish the range of the significant ROTI occurrence range and the remarkable ROTI value enhancements during events.

All presented ROTI series reveal similar quiet-time behavior, but with some differences associated with the solar activity changes. During high solar activity, ROTI values above $0.4 \mathrm{TECU} / \mathrm{min}$ were observed at latitudes between $\sim 70^{\circ} \mathrm{N}$ and $\sim 80^{\circ} \mathrm{N}$, with an equatorward expansion down to $\sim 65^{\circ} \mathrm{N}$ during night. During the high solar activity period, the ROTI values above $0.5 \mathrm{TECU} / \mathrm{min}$ were observed almost every day. During low solar activity (2017), ROTI values were overall smaller and located within a more narrow latitudinal range- between $75^{\circ} \mathrm{N}$ and $80^{\circ} \mathrm{N}$ during the day and $70^{\circ} \mathrm{N}$ and $80^{\circ} \mathrm{N}$ MLat at night.

In general, an average position of the auroral ionospheric irregularities' equatorward boundary typically varies near $70-75^{\circ} \mathrm{N}$ of geomagnetic latitude during local daytime and around $65-70^{\circ} \mathrm{N}$ during local nighttime conditions.

The color plots of the ROTI series reveal a "spiked structure"-the downward spikes corresponding with the occasional equatorward expansion of the high ROTI values during intense geomagnetic activity events.

Peaking values of both Ap and AE indices have an immediate response in ROTI enhancements at high latitudes and increased ROTI value occurrences at much lower latitudes. We selected several of the highest values of the Ap index in each analyzed year and compared them with AE values, ROTI maxima, and the high ROTI values (Table 3). 


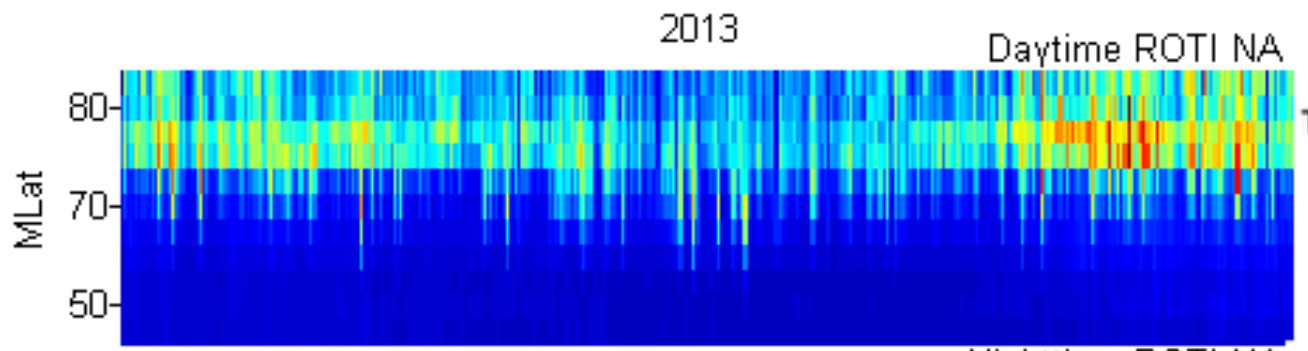

$\mathrm{TECU} / \mathrm{min}$
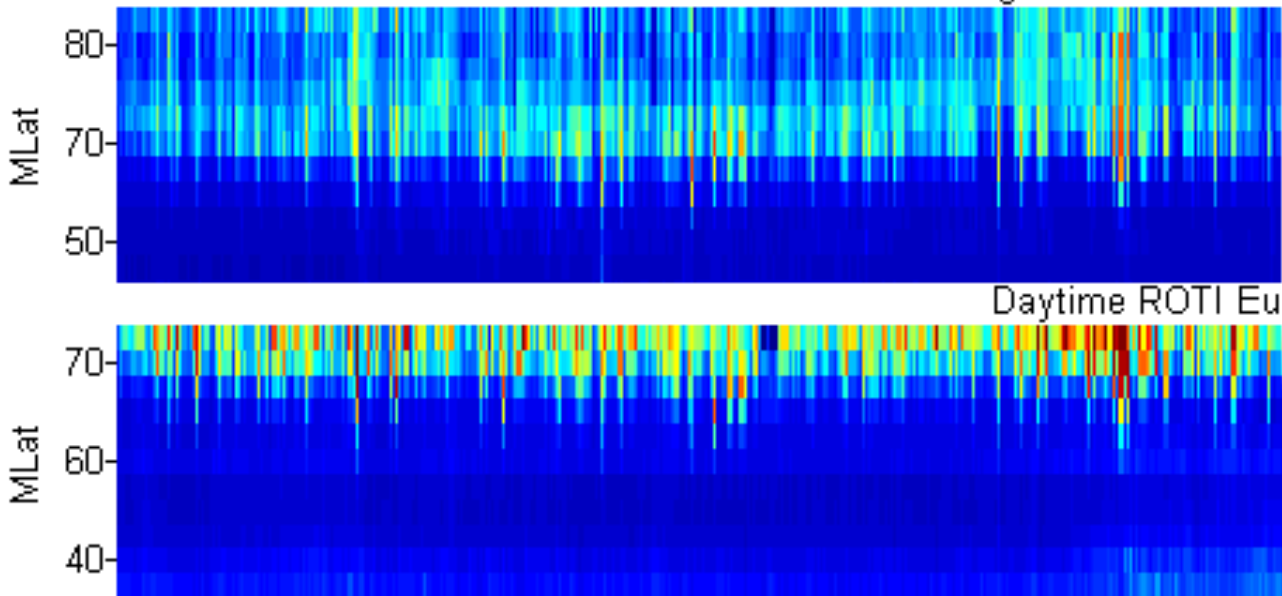

Nighttime ROTI Eu
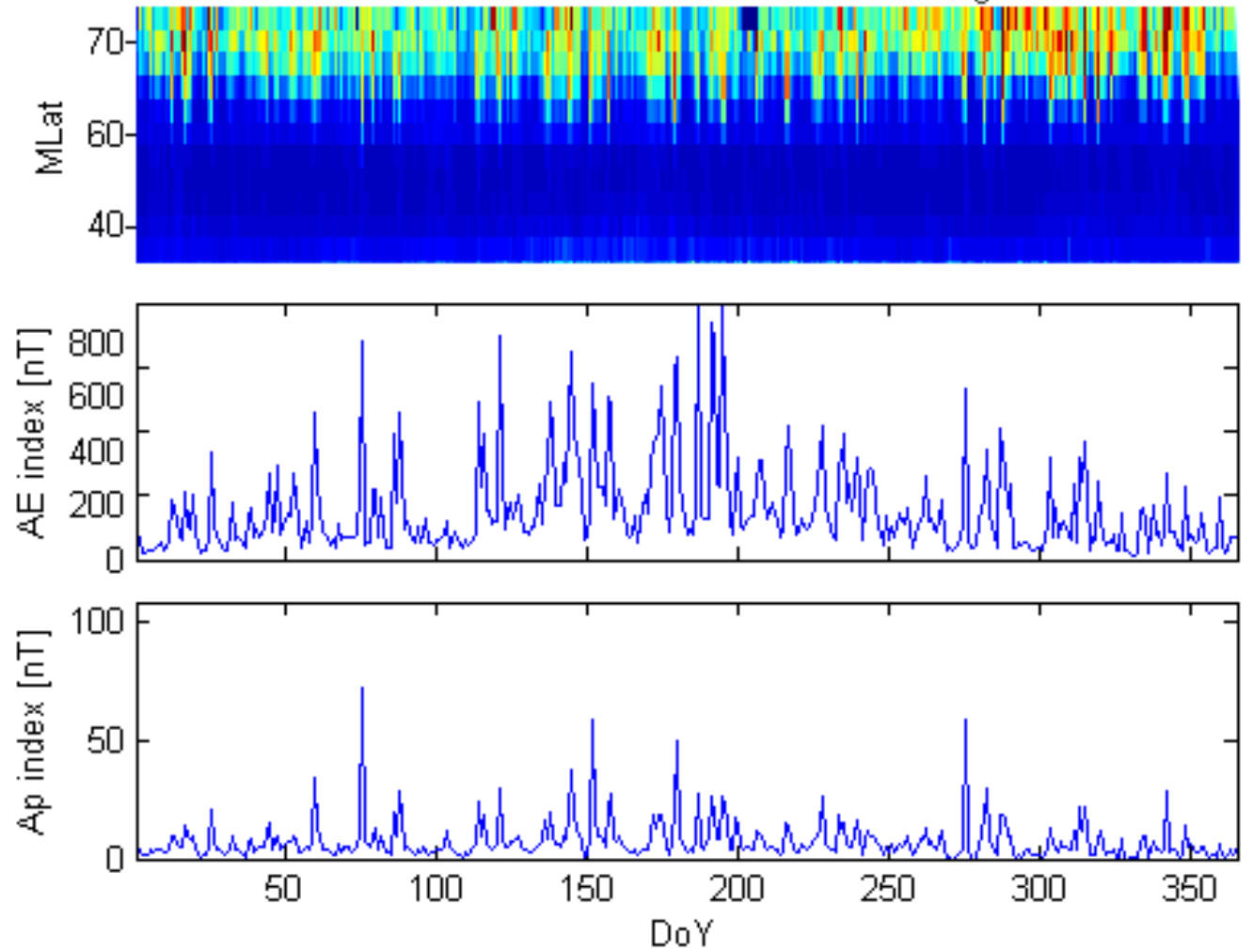

Figure 5. The long-term ROTI time-series in the North-American sector (panels 1 and 2 from the top-local daytime and nighttime series, respectively) and in the European sector (panels 3 and 4 from the top-daytime and nighttime series respectively), AE index time-series (panel 5 from the top), and Ap index time-series (the bottom panel)_for the year 2013. 

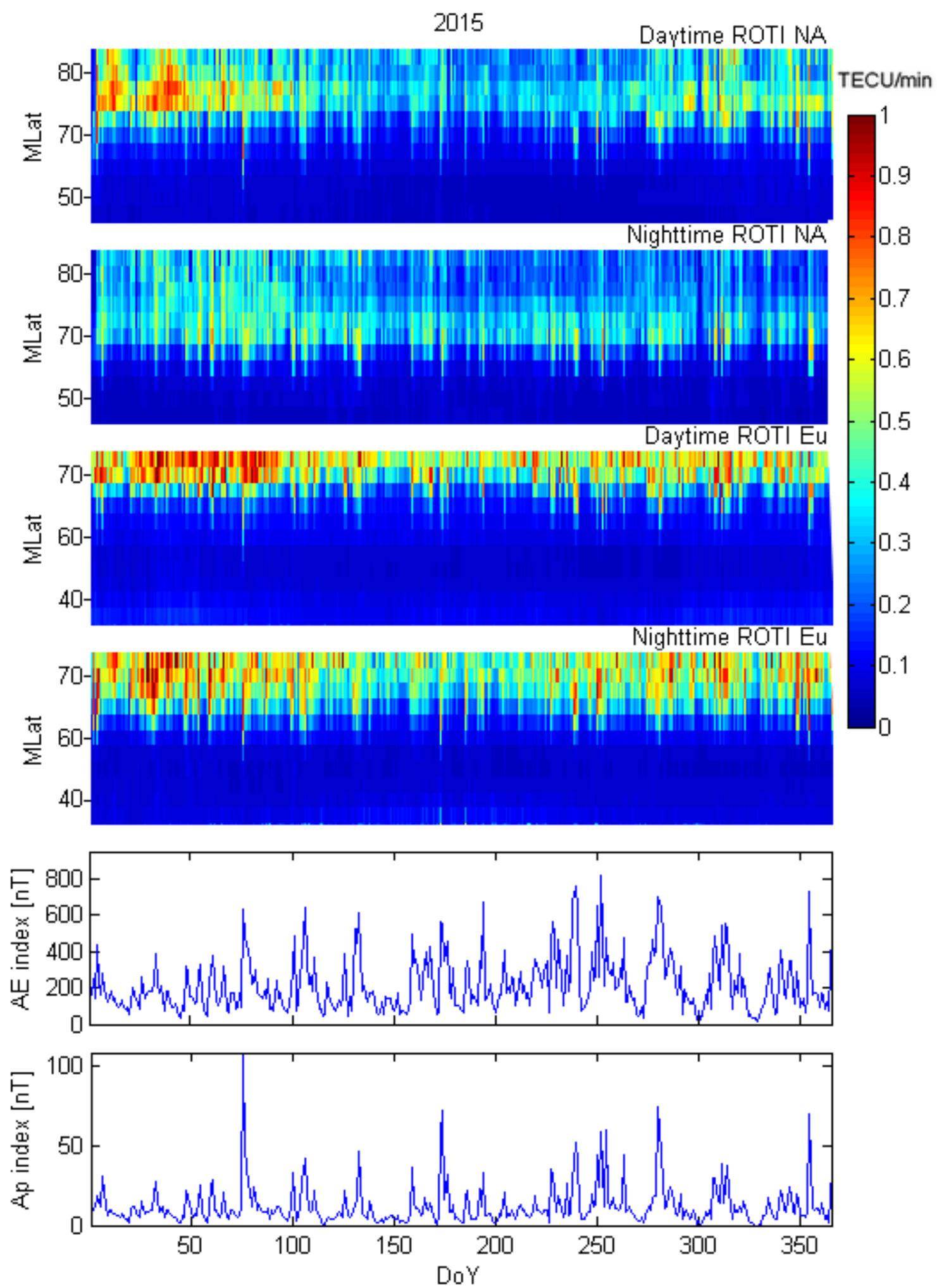

Figure 6. The same as Figure 5 but for the year 2015. 

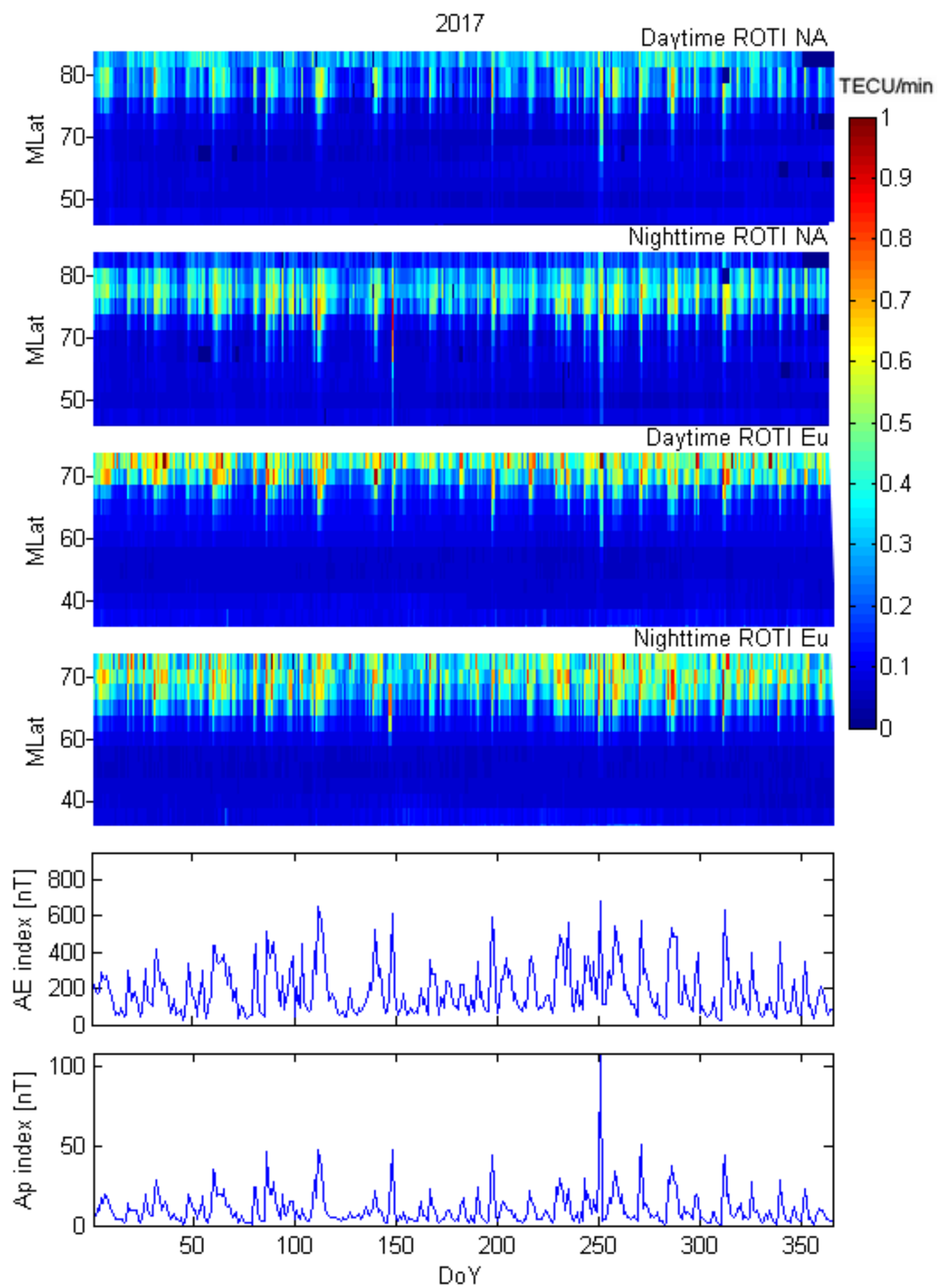

Figure 7. The same as Figure 5 but for the year 2017. 
Table 3. High Ap and AE values compared with ROTI behavior (maximum value and equatorward spread).

\begin{tabular}{lllllll}
\hline $\begin{array}{l}\text { Date of the } \\
\text { Event }\end{array}$ & $\begin{array}{l}\text { Ap } \\
\text { (Daily) }\end{array}$ & $\begin{array}{l}\text { Ap } \\
\text { max }\end{array}$ & $\begin{array}{l}\text { AE (Daily) } \\
\text { [nT] }\end{array}$ & $\begin{array}{l}\text { AE max } \\
\text { [nT] }\end{array}$ & $\begin{array}{l}\text { Daily ROTI } \\
\text { Peak }\end{array}$ & $\begin{array}{l}\text { Lowest MLat of } \\
\text { High ROTI }\end{array}$ \\
\hline $2013 / 076$ & 72 & 111 & 684 & 2571 & 1.0735 & $55^{\circ} \mathrm{N}$ \\
$2013 / 152$ & 58 & 132 & 546 & 1645 & 0.7331 & $60^{\circ} \mathrm{N}$ \\
$2013 / 275$ & 58 & 179 & 528 & 2087 & 0.9189 & $55^{\circ} \mathrm{N}$ \\
$2015 / 076$ & 108 & 179 & 633 & 2269 & 0.8900 & $50^{\circ} \mathrm{N}$ \\
$2015 / 174$ & 72 & 179 & 555 & 2212 & 0.7207 & $55^{\circ} \mathrm{N}$ \\
$2015 / 280$ & 74 & 154 & 697 & 1839 & 0.7484 & $60^{\circ} \mathrm{N}$ \\
$2015 / 354$ & 70 & 111 & 726 & 1946 & 0.9969 & $55^{\circ} \mathrm{N}$ \\
$2017 / 148$ & 47 & 132 & 617 & 1960 & 0.6777 & $60^{\circ} \mathrm{N}$ \\
$2017 / 197$ & 44 & 80 & 590 & 1748 & 0.7097 & $60^{\circ} \mathrm{N}$ \\
$2017 / 251$ & 106 & 236 & 677 & 2677 & 1.1066 & $50^{\circ} \mathrm{N}$ \\
\hline
\end{tabular}

Table 3 clearly shows that stronger geomagnetic events (with AE exceeding values of $2000 \mathrm{nT}$ triggering a stronger response in ROTI values and high ROTI spreading towards the equator.

In the European sector, due to the station distribution, the latitudinal slices of ROTI cover mainly the low-to-mid part of the auroral irregularity oval. In the North-American sector with a more favorable configuration of GNSS stations-the ROTI observations reveal a clear poleward boundary of the auroral irregularity oval around $80-85^{\circ} \mathrm{N}$ during local daytime and down to $75^{\circ} \mathrm{N}$ during local nighttime conditions, depending on the season and solar cycle phase. The poleward boundary of the auroral oval is also vulnerable to the disruptions caused by intense geomagnetic activity. The poleward boundary moves further poleward during severe geomagnetic storms.

We found that the ROTI daily average values were larger in the second half of the year 2013 and the first half of 2015. There were no significant enhancements in the geomagnetic indices, but these periods are around the 24th solar cycle maximum (at the turn of 2013 and 2014, as shown in Figure 1) and thus the background TEC was also larger.

In order to illustrate the diurnal variability of ROTI-based characteristics of ionospheric irregularities' occurrence, we calculated ROTI hourly averages; and taking into account the seasonal variation as well, we divided the results into separate seasons (centered for March, June, September, and December). The seasonal averages can be treated as quiet-time ionosphere description, as the considered 24th solar cycle was characterized by moderate/low overall activity, so occasional geomagnetic events were smoothed-out by three-month averaging.

Presented annual sets of daytime/nighttime ROTI observations also demonstrate some characteristics of the seasonal and annual variability of the high-latitude ionospheric irregularities' occurrence, but the used 12-h averaging potentially whites out all daily variations (besides most general day-night differences). In order to examine the day-to-day changes and repeatability of the ionospheric irregularities patterns, we calculated the autocorrelation of each latitudinal ROTI time-series. For a detailed analysis, we used the basic 5-min data. The derived autocorrelation results for the European and North-American sectors for the years of 2013, 2015, and 2017 subsequently are shown in Figure 8. 

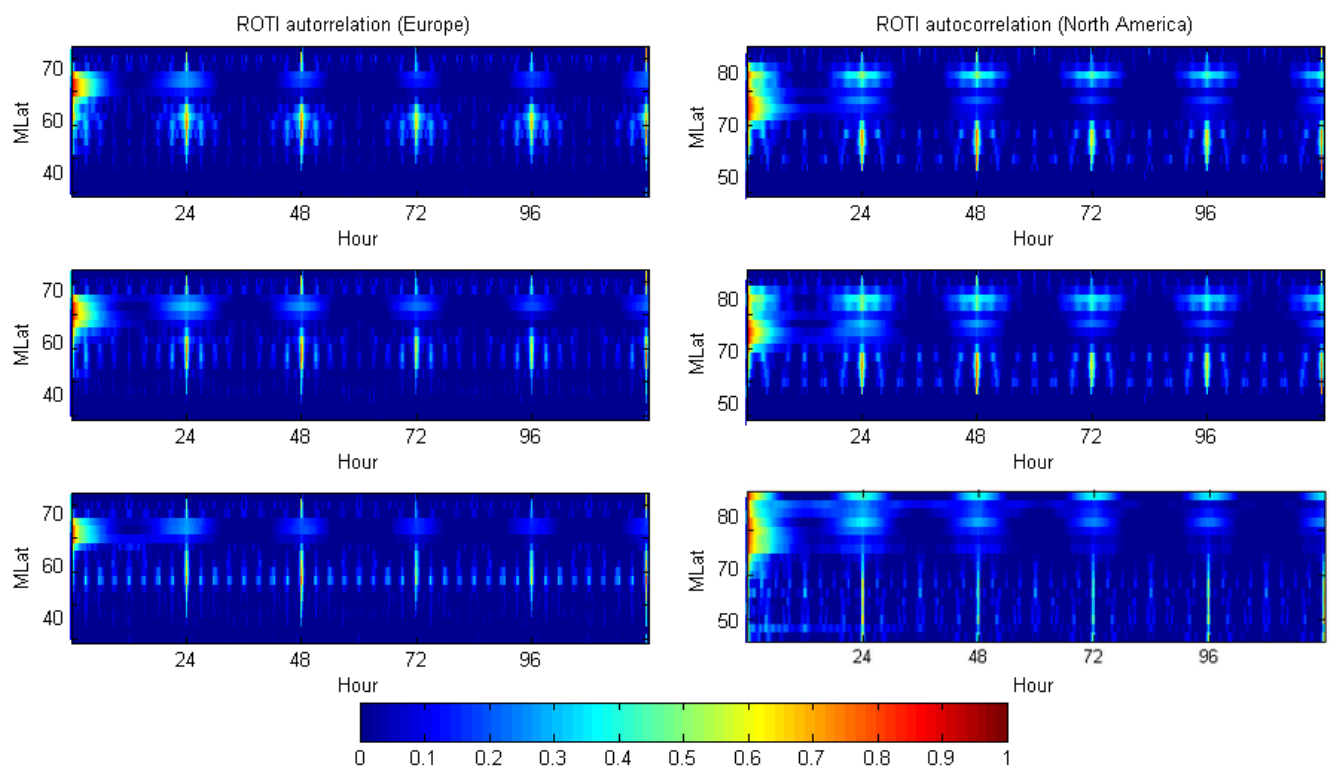

Figure 8. ROTI autocorrelation results as a function of magnetic latitude and time for European (left column) and North-American (right column) sectors for years 2013, 2015 and 2017 respectively.

The autocorrelation analysis shows in the first place a strong autocorrelation for the lags of 24 , $48 \mathrm{~h}$, and the following 24-h multiples. Values for those lags exceed level of 0.6. This makes it possible to conclude that there is a daily repeatable pattern in the ROTI time-series; however, this is only valid for middle geomagnetic latitudes (below $60-70^{\circ} \mathrm{N}$ ), so below the area of strong ionospheric irregularities' occurrence. At high latitudes, the autocorrelation seems to be blurred and high values occur only for lags below $2 \mathrm{~h}$. The low-to-intense ionospheric irregularities are present almost all the time within the auroral oval zone independently of the geomagnetic and solar activity level (cf., Figure 9). Additionally, some autocorrelations could be spotted for $\sim 3$-h lags; however, their values do not exceed the level of 0.4 .

Figure 9 shows several examples of the IGS ROTI maps in a polar view illustrating the auroral oval of the ionospheric irregularities as derived from multi-station GNSS observations. The maps were constructed in the 00-24 magnetic local time (MLT) domain.

The sequence of the diurnal ROTI maps presented an evolution of the ionospheric irregularities oval before, during, and after moderate geomagnetic storms. At the background quiet time, the ionospheric irregularities were found to be more pronounced during a high solar activity period (year of 2015). The intensity, shape, and location of the irregularities oval during disturbed conditions mainly depend on geomagnetic storm's intensity and duration for both low and high solar activity periods.

Despite different conditions of solar activity level, it can be noted that ionospheric irregularities of moderate intensity are observed permanently within the oval, which explains a low day-to-day autocorrelation (on 24-h lags), as presented in Figure 8. The oval is also stretched more equatorwards at the night side and reaches latitudes of $60^{\circ}-70^{\circ} \mathrm{N}$ MLat-similarly to the results presented in Figures 5-7. Figure 8 demonstrated that there should be a daily repeatability of ROTI patterns seen (at least for latitudes below $70^{\circ} \mathrm{N}$ ), and we examined the daily variability signatures in more detail (below). 

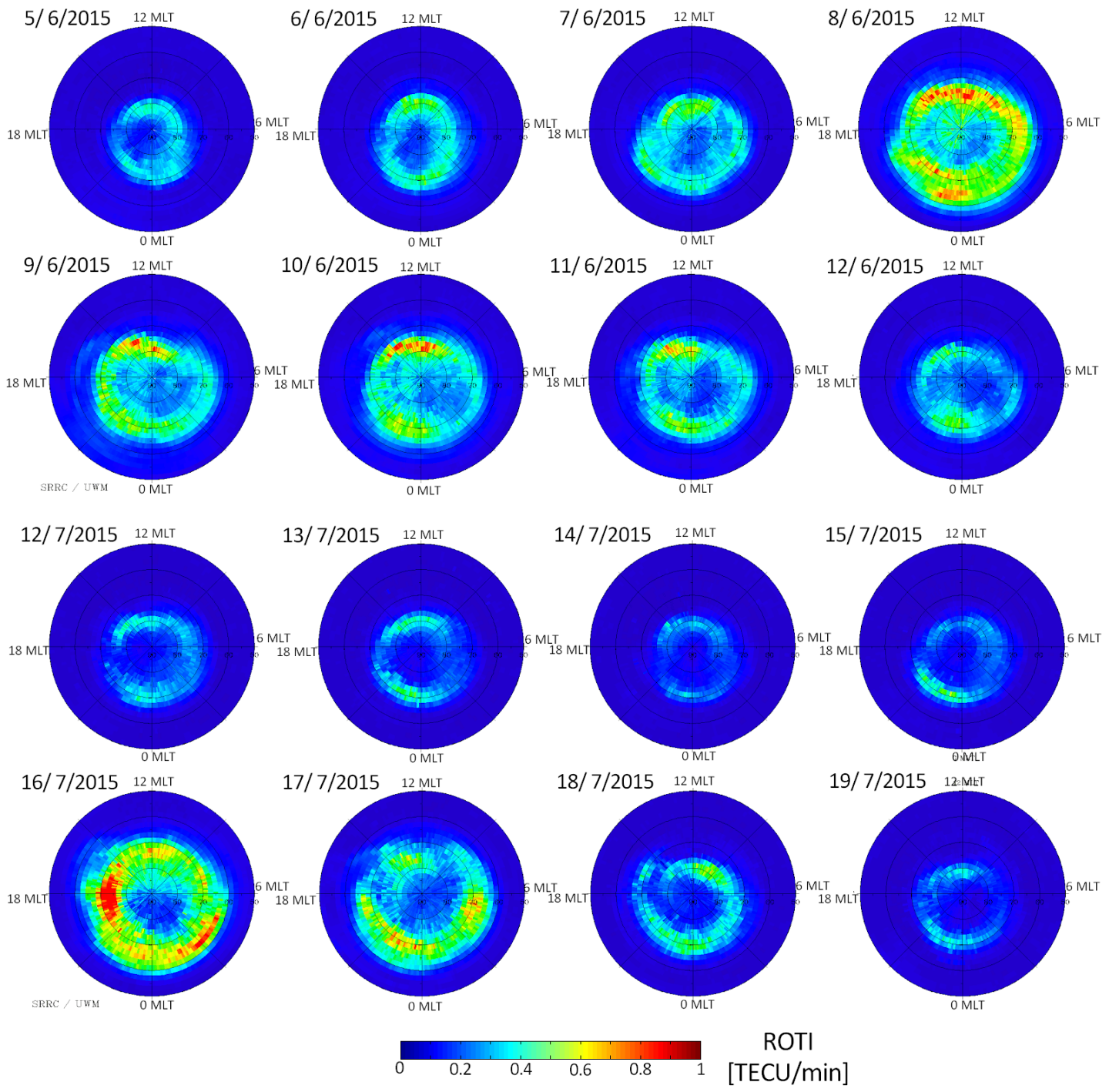

TECU/min]

Figure 9. IGS ROTI product-auroral oval of the ionospheric irregularities (ROTI) for the 24 solar cycle maximum (2015, summer) and solar minimum for the same season. The maps cover $50^{\circ}-90^{\circ} \mathrm{N}$ MLat with $10^{\circ}$ latitude circles; magnetic local noon/midnight is at the top/bottom, and dusk/dawn is toward the left/right. Source: http://srrc.uwm.edu.pl/content/igs-roti-fluctuations-map\#overlay=node/add.

To analyze the average characteristics of diurnal ROTI variability, we calculated the hourly ROTI averages in terms of L.T., taking into account different seasons- the entire dataset was divided into twelve subsets: four seasonal (March, June, September, and December-centered) subsets for every year. The seasonal averages can be treated as quiet-time ionosphere descriptions, as the considered 24th solar cycle was characterized by moderate/low overall activity, so occasional geomagnetic events were smoothed-out by the applied three-month averaging. Figures 10 and 11 present the results for the European and the North-American regions, respectively. For every seasonal subplot, we also superimposed the equatorward boundary of the auroral oval, as derived from the Zhang and Paxton [33] empirical model of the auroral oval that was implemented into the recent version of the International Reference Ionosphere-IRI-2016 [34]. This model is a Kp-dependent global auroral model developed based on global far ultraviolet auroral data collected by Thermosphere Ionosphere Mesosphere Energetics and Dynamics (TIMED)/Global Ultraviolet Imager (GUVI). 


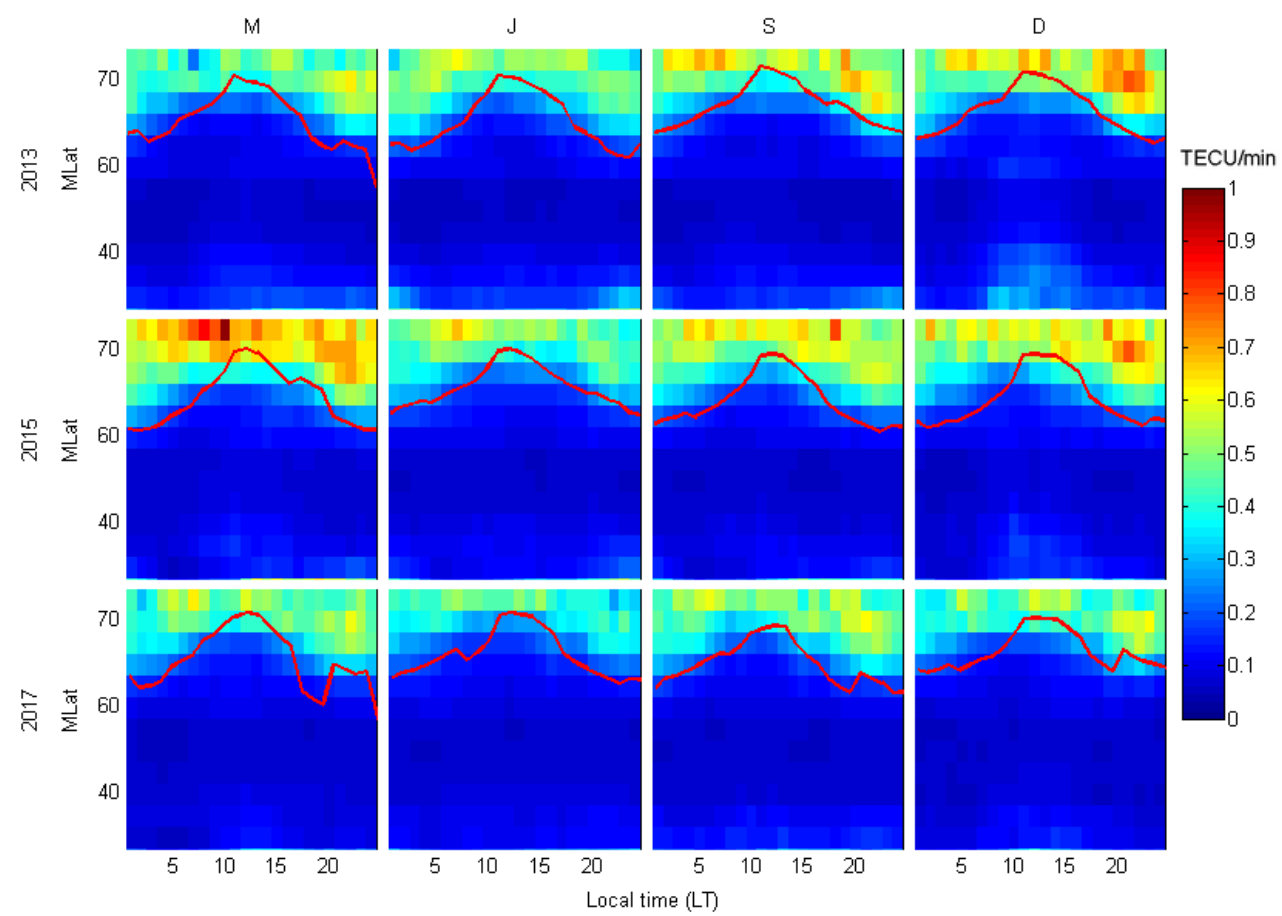

Figure 10. ROTI seasonal (March, June, September, and December-centered seasons) averages of the ROTI values in 2013, 2015, and 2017 (in subsequent rows respectively) as a function of magnetic latitude (MLat) and time (TT, hours). European sector. The red line shows the equatorward boundary of the auroral oval provided by the IRI-2016 model.

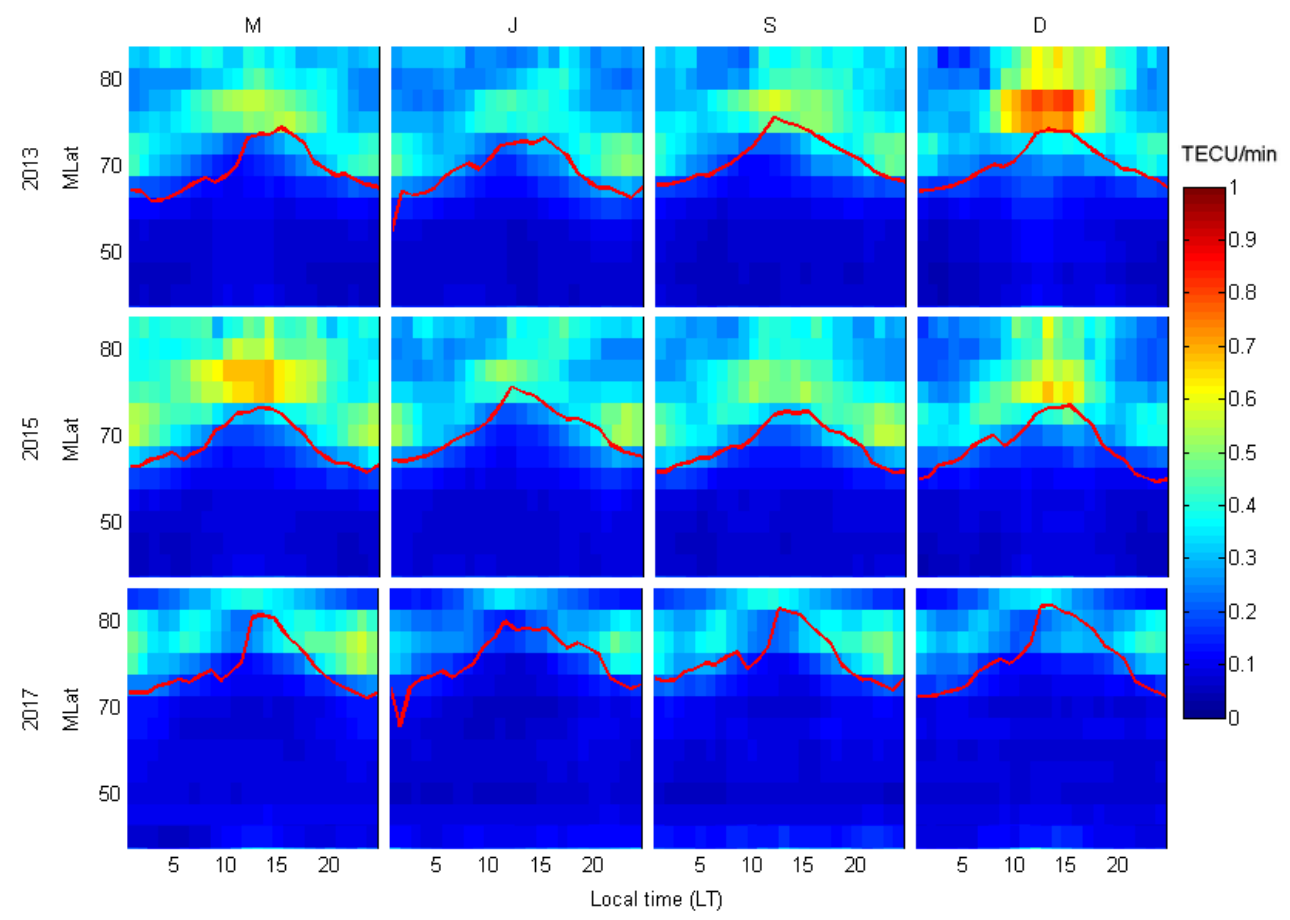

Figure 11. The same as Figure 8 but for the North-American sector.

The seasonal averages of hourly ROTI values presented as a function of MLT and MLat in Figures 10 and 11 demonstrate a similar daily trend as single-day observations (Figure 9)—the equatorward boundary of the ionospheric irregularities region expands equatorwards during magnetic night and demonstrates a more poleward location during local daytime. That is a typical behavior 
of the auroral oval corresponding to the observations and current empirical models of the auroral oval. Additionally, the maximum of ROTI obviously shifts equatorward during local nighttime, as was also shown for ROTI observations in [37], and well agreed with the concept of the auroral oval (e.g., $[35,38,39])$. A daytime localized ROTI increase close to the magnetic noon can be associated with particle precipitation into the polar cusp region. In Figure 11 one can also note a pronounced drop in the irregularities intensity at higher latitudes (around $80^{\circ} \mathrm{N}$ ) during nighttime-this also corresponds to the quiet-time auroral oval poleward border in Figure 9-irregularities surround the north magnetic pole in a ring-like structure, decreasing significantly in the closest vicinity of the pole [36]. Thus, for the North-American region, the ROTI-based analysis can detect both the poleward and equatorward boundaries of the irregularities oval.

The border is sharper in the local winter half of the year (March and December-centered seasons). Additionally, the average ROTI values were found to be higher during winter seasons. This can be explained by the sunlight conditions during polar day/night which impact quiet-time, large-scale plasma gradient formation at high latitudes.

The winter-summer differences become less evident in 2017 (c.f. June and December results in Figures 8 and 9, when the background ionospheric plasma density level and the whole activity were very low due to the deep solar cycle minimum). During the whole 2017, the ionospheric irregularities oval was narrower-about five degrees closer to the north magnetic pole-than that of the years with a higher solar activity level.

Additionally, we note that the latitudinal spread of the irregularities oval corresponds well to the equatorward border of the auroral oval derived from the Zhang and Paxton model (red lines in Figures 8 and 9 .

Thus, our results confirm repeatable signatures of ROTI occurrence at high latitudes as observational evidence for presence of low-to-moderate intensity ionospheric irregularities within the auroral oval zone at all levels of solar activity and quiet-time conditions. The most dramatic intensification of ROTI at high latitudes is usually a result of geomagnetic activity increases.

As it was shown in Figures 5-7, jumping values of AE and Ap indices have a direct response in ROTI results, both in the magnitude and in the expansion of latitudinal range of high ROTI values. To examine the latitudinal dependence of ROTI on geomagnetic conditions in more detail, we calculated linear correlation coefficients between the AE index and each latitudinal ROTI time-series. Figure 12 presents results of correlation analysis between the AE index and ROTI values for the European and North-American sectors for different years.

The results in Figure 12 demonstrate that the linear correlation coefficient reaches the largest values at high latitudes (above $\sim 55-60^{\circ} \mathrm{N}$ ). This correlation is considered as a strong one. The largest values $(\mathrm{R} \sim 0.8)$ are registered within a narrow latitudinal range of $\sim 60^{\circ} \mathrm{N}-70^{\circ} \mathrm{N}$, but large values of correlation $(\mathrm{R}>0.6)$ are found at lower latitudes down to $\sim 50-55^{\circ} \mathrm{N}$, depending on the conditions. It is interesting to note that poleward of $70^{\circ} \mathrm{N}$ MLat, the correlation value rapidly drops below 0.4 in both longitudinal sectors. Thus, the most pronounced correlation between the AE index and ROTI was found within a relatively narrow latitudinal zone of $55-70^{\circ} \mathrm{N}$ MLat-that means that ROTI displays a selective latitudinal sensitivity and with a rapid AE increase; the ROTI magnitude increase should be expected mostly within this zone, associated with an auroral oval expansion. This confirms that occurrences of intense ionospheric irregularities within the auroral oval are driven mostly by geomagnetic factors.

A general view on the ROTI series in Figures 5-7 reveals a noticeable equatorward move of the irregularities zone that corresponds to the night-side spread of the auroral oval. It has straightforward equivalence in the ROTI/AE correlation. The high correlation bulge in all plots is more extended for the nighttime data-night ROTI is more sensitive to geomagnetic activity independently of the sector and solar cycle phase. Additionally, during high solar activity, ROTI sensitivity to AE index spreads further equatorward. 

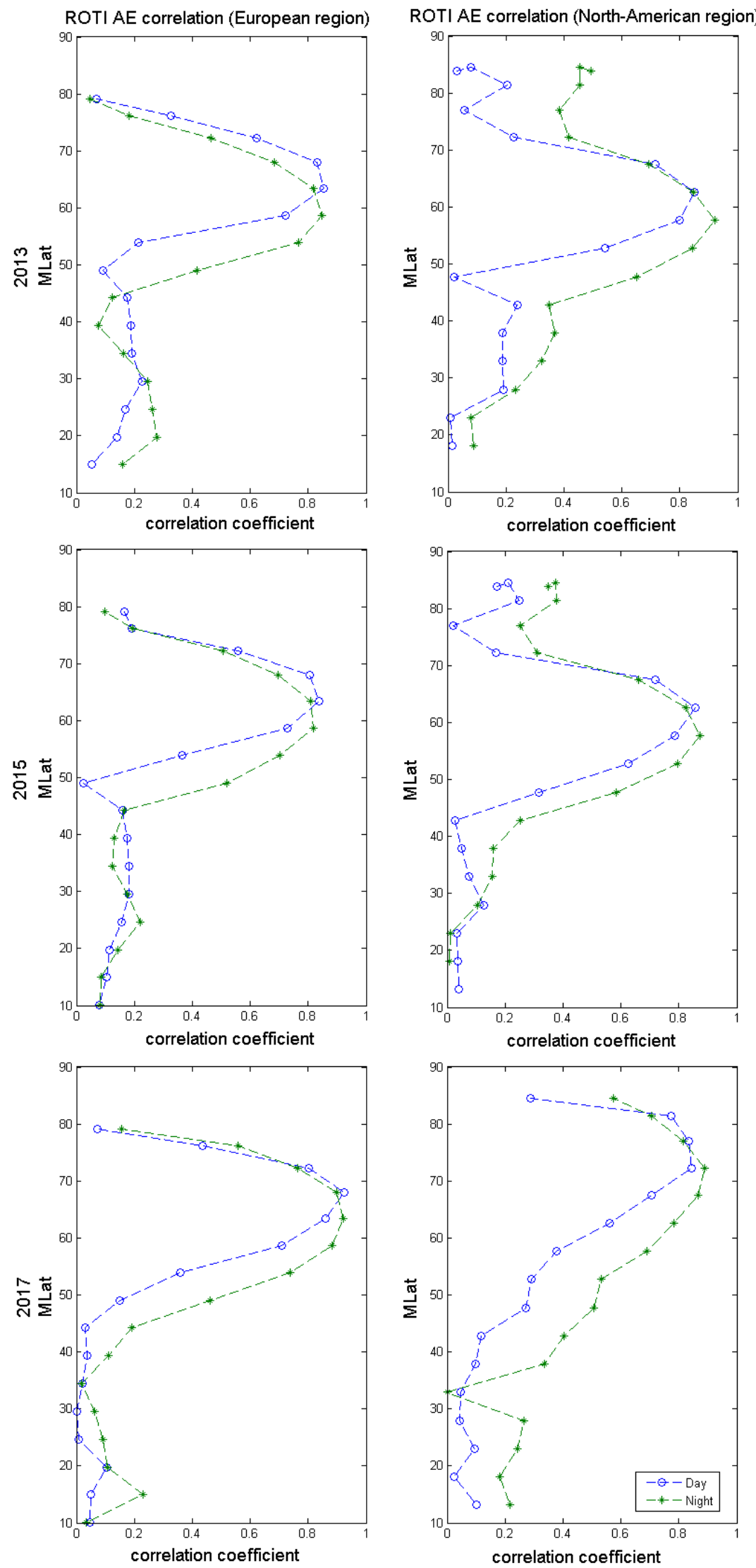

Figure 12. Linear correlation coefficient values between ROTI and AE indexes on different magnetic latitudes in European and North-American sectors in years 2013, 2015 and 2017. 
Occurrence of mid-latitude plasma density structures in the ionosphere and the auroral oval expansion towards middle latitudes are mostly driven by geomagnetic activity, whereas at high geomagnetic latitudes, ionospheric irregularities occur most of the time within the auroral oval zone- - high geomagnetic activity enhances their strength and the size of this zone.

\section{Discussion and Conclusions}

In this study, we analyzed three representative year-long periods based on time series of the GNSS-based ROTI values in two sectors-European and North-American-in order to assess the climatological characteristics of mid and high-latitude ionospheric irregularities. We have assessed the ROTI-described ionospheric irregularities in of the daily variation and daily repeatability, seasonal and solar cycle variations, and correlations with indices describing magnitudes of geomagnetic disturbances to find the climatological signatures of the ROTI-derived TEC fluctuations.

The long-term analysis of ROTI shows that the GNSS technique could be successfully used to describe the morphology and evolution of the ionospheric irregularities. ROTI is quite sensitive to rapid changes in the geomagnetic conditions. Thus, ROTI can be used to describe quiet-time ionospheric irregularity occurrences and to characterize GNSS signal fluctuation level enhancement, and its spatial expansion during serious geomagnetic events of different intensity.

Since phase fluctuations detected by ROTI are related to radio signal scintillations, the ROTI data product can be a very useful tool to describe ionospheric plasma density irregularity occurrences on a global scale. This technique does not require any additional equipment, aside from currently present and widely-available GNSS permanent networks.

Many of the GNSS scintillation studies are devoted to the signal amplitude scintillations. There is observational evidence that signal amplitude scintillations are rather rare in the polar zone-signal phase scintillations are more typical for this region. Thus, for mid-to-high latitudes, it is of crucial importance to perform a continuous monitoring of phase fluctuation activity based on GNSS observations. We also emphasize that climatological ROTI characteristics obtained in this study are in very good agreement with the high rate phase scintillation $(\sigma \phi$, sigma phi) climatology at the high and subpolar latitudes [40]. Similar correspondence can be found in amplitude scintillation studies-despite the fact that intensity scintillations are more typical for the equatorial zone, there are also signatures of intensity scintillation occurrence within the auroral oval zone [41].

The average quiet-time ROTI climatological characteristics also agreed well with the empirical models describing the auroral oval position. In particular, the IRI-2016 model provides now the equatorward boundary of the auroral oval derived from the Zhang and Paxton empirical model [33]. The diurnal variation of the polar region irregularities specified by ROTI demonstrated that these irregularities mainly occur within auroral oval boundaries, as determined by this empirical model. Both the noticeable ROTI and auroral oval boundary variations demonstrate similar behavior with with the seasonal and solar cycle variations. This agreement is equally strong at both longitudinal sectors (European and North-American).

Currently, the IGS provides ROTI maps for the Northern hemisphere-a product, specified the daily ROTI pattern at high latitudes [19]. In Figure 9, we demonstrate several examples of the diurnal behavior of the ionospheric irregularity oval in different conditions. In this work, we assessed the ROTI behavior in long-term, climatological scales and found a clear correlation of our results with the single (quiet or disturbed) day IGS ROTI maps.

For our long-term analysis, we considered spatio-temporal variability of ROTI along two specific longitudes, which represent cuts of the auroral irregularity oval at two different sectors. This geographical separation allowed us to perform the analysis for two sectors with dense and broad networks of GNSS users in the Northern hemisphere. We recognized the important characteristics of the ionospheric irregularity pattern in quiet and disturbed conditions. For all levels of solar activity, an obvious prevailing of ionospheric irregularity occurrences at local night-side was registered. The equatorward border of the irregularities zone is typically located at lower latitudes 
during local nighttime-around five degrees lower than those of daytime. This also agreed well with the phase scintillation climatology [40]—despite a maximum probability of phase scintillation occurrence appearing around noon, the overall enhanced probability is shifted further equatorward during nighttime.

A number of authors have utilized ROTI during specific case-studies of intense geomagnetic storms $[21,42,43]$. Climatological characteristics specified by average ROTI values reveal also a clear sensitivity to the geomagnetic activity disturbances (as proven on example of $\mathrm{AE}$ and ap indices). Geomagnetic events trigger a direct response in irregularities patterns described by ROTI-the maximum value rises and the zone of enhanced ROTI value spreads equatorward, reaching mid-latitudes. During intense geomagnetic activity events, the ROTI magnitude reaches larger values of $1 \mathrm{TECU} / \mathrm{min}$ and above, whereas the irregularities zone expands equatorward down to even $50^{\circ} \mathrm{N}$ MLat depending on the storm magnitude. The pronounced asymmetrical day-side/night-side oval stretch is driven by the geomagnetic conditions (e.g., IMF By) and the specific time of the storm commencement.

Results of our analysis confirm a very good performance of the ROTI-based approach for characterization of the ionospheric plasma irregularities climatology in the mid and high-latitude regions. ROTI values describe very well the temporal and spatial evolution of the ionospheric irregularities within the auroral region during the local day-night cycle at non-disturbed conditions. These results also confirmed a rather high sensitivity of the ROTI index in detecting and specifying features of plasma irregularity occurrences against seasonal changes and solar ionisation level during the period we examined.

One of the most solid directions now is the existing opportunity of a near-real-time nowcasting of the ionospheric fluctuations with ROTI maps obtained with rapid, multi-site RINEX data. We can consider the ROTI technique as a pure data-driven model and a good candidate for a near-real-time nowcaster of the ionospheric irregularities' occurrence, limited only by the data availability (data streaming) and hardware capacity. Furthermore, the existing historical GNSS observations and ROTI products have great potential to serve as valuable datasets for assessments and evaluations of currently used models for auroral oval location and boundaries. Since ROTI is derived directly from the radio beacon observations, we also aim to perform a comparison with other types of radio signal measurement, e.g., radio astronomical observations. In particular, the Low Frequency Array (LOFAR) telescope performs observations in low radio frequencies that are very vulnerable to ionospheric disturbances. Simultaneous observations of astronomical radio sources, such as supernova remnant Casiopeia A, radio galaxy Gygnus A, and bright pulsars, together with ground-based GNSS ROTI observations could bring fascinating insights to the morphologies of ionospheric disturbances' impacts on different radio frequencies.

Author Contributions: Conceptualization, K.K., I.Z., and A.K.; methodology, I.Z., A.K., I.C. and N.W.; software, K.K. and A.F.; validation, K.K. and I.Z.; formal analysis, I.Z., A.K., and K.K.; investigation, K.K. and A.F.; resources, K.K., I.Z., A.F. and N.W.; data curation, K.K., A.F. and N.W.; writing-original draft preparation, K.K., I.Z., and A.K.; writing-review and editing, K.K., I.Z., A.K., and I.C.; visualization, K.K. and A.F.; supervision, A.K. and I.Z.; project administration, A.K. and I.C.; funding acquisition, A.K. and I.C. All authors have read and agreed to the published version of the manuscript.

Funding: The UWM contribution is supported by the National Centre for Research and Development, Poland, through grant ARTEMIS (decision numbers DWM/PL-CHN/97/2019 and WPC1/ARTEMIS/2019) and the National Science Centre, Poland, through grant 2017/27/B/ST10/02190. The UWM authors thank also for their support the Ministry of Science and Higher Education (MSHE), Poland, for granting funds for the Polish contribution to the International LOFAR Telescope (MSHE decision number DIR/WK/2016/2017/05-1) and for maintenance of the LOFAR PL-612 Baldy (MSHE decision number 59/E-383/SPUB/SP /2019.1).

Acknowledgments: The study was based on the raw GNSS data provided by the European Permanent Network through BKGE (ftp://igs.bkg.bund.de/euref/obs), CORS (ftp://geodesy.noaa.gov), and Natural Resources Canada (webapp.geod.nrcan.gc.ca). We acknowledge NASA/GSFC's Space Physics Data Facility's OMNIWeb service for geophysical parameters data (https://omniweb.gsfc.nasa.gov/ow_min.html) and International Reference Ionosphere information (https: / / ccmc.gsfc.nasa.gov/cgi-bin/modelweb/models/vitmo_model.cgi).

Conflicts of Interest: The authors declare no conflict of interest. 


\section{Abbreviations}

The following abbreviations are used in this manuscript:

$\begin{array}{ll}\text { GNSS } & \text { Global Navigation Satellite Systems } \\ \text { LOFAR } & \text { Low Frequency Array } \\ \text { TEC } & \text { Total Electron Content } \\ \text { STEC } & \text { Slant Total Electron Content } \\ \text { IGS } & \text { International GNSS Service } \\ \text { LOS } & \text { Line of Sight } \\ \text { IPP } & \text { Ionosphere Piercing Point } \\ \text { ROT } & \text { Rate of TEC } \\ \text { ROTI } & \text { Rate of TEC Index } \\ \text { EPN } & \text { EUREF Permanent Network } \\ \text { CORS } & \text { Rate of TEC Index } \\ \text { NRCAN } & \text { Rate of TEC Index } \\ \text { RINEX } & \text { Receiver Independent Exchange System } \\ \text { GLAT } & \text { Geodetic Latitude } \\ \text { GLON } & \text { Geodetic Longitude } \\ \text { MLat } & \text { Geomagnetic Latitude } \\ \text { LT } & \text { Local time } \\ \text { MLT } & \text { Magnetic local time } \\ \text { IRI } & \text { International Reference Ionosphere } \\ \text { GUVI } & \text { Global Ultraviolet Imager } \\ \text { TIMED } & \text { Thermosphere Ionosphere Mesosphere Energetics and Dynamics }\end{array}$

\section{References}

1. Pi, X.; Mannucci, A.J.; Lindqwister, U.J. Ho CM Monitoring of global ionospheric irregularities using the worldwide GPS network. Geophys. Res. Lett. 1997, 24, 2283-2286. [CrossRef]

2. Wanniger, L. Monitoring ionospheric disturbances using IGS Network. In IGS Workshop Proceedings, Special Topics and New Direction; Gendt, G., Dick, G., Eds.; GeoForschungsZentrum: Potsdam, Germany, 1995; pp. 57-66.

3. Jakowski, N.; Béniguel, Y.; De Franceschi, G.; Hernández-Pajares, M.; Jacobsen, K.S.; Stanislawska, I.; Tomasik, L.; Warnant, R.; Wautelet, G. Monitoring, tracking and forecasting ionospheric perturbations using GNSS techniques. J. Space Weather Space Clim. 2012, 2. [CrossRef]

4. Hernández-Pajares, M.; Juan, J.M.; Sanz, J.; Aragón-Àngel, A.; García-Rigo, A.; Salazar, D.; Escudero, M. The ionosphere: Effects, GPS modeling and the benefits for space geodetic techniques. J. Geod. 2011, 85, 887-907. [CrossRef]

5. Aarons, J. Global positioning system phase fluctuations at auroral latitudes. J. Geophys. Res. 1997, 102, 17219-17231. [CrossRef]

6. Aarons, J.; Lin, B. Development of high latitude phase fluctuations during the 10 January, 10-11April, and 15 May 1997 magnetic storms. J. Atmos. Sol. Terr. Phys. 1999, 61, 309-327. [CrossRef]

7. Phelps, A.D.R.; Sagalyn, R.C. Plasma density irregularities in the high-latitude top side ionosphere. J. Geophys. Res. 1976, 81, 515-523. [CrossRef]

8. Wernik, W.A.; Secan, J.A.; Fremouw, E.J. Ionospheric irregularities and scintillation. Adv. Space Res. 2003, 31, 971-981. [CrossRef]

9. Krankowski, A.; Shagimuratov, I.; Baran, L.; Ephishov, I. Study of TEC fluctuations in Antarctic ionosphere during storm using GPS observations. Acta Geophys. Pol. 2005, 53, 205-218.

10. Watson, C.; Jayachandran, P.T.; Spanswick, E.; Donovan, E.F.; Danskin, D.W. GPS TEC technique for observation of the evolution of substorm particle precipitation. J. Geophys. Res. 2011, 116. [CrossRef]

11. Secan, J.A.; Bussey, R.M.; Fremouw, E.J.; Basu, S. An improved model of equatorial scintillation. Radio Sci. 1995, 30, 607-617. [CrossRef]

12. Béniguel, Y. Global Ionospheric Propagation Model (GIM): A propagation model for scintillations of transmitted signals. Radio Sci. 2002, 37. [CrossRef] 
13. Béniguel, Y.; Angling, M.; Banfi, E.; Bourga, C.; Cueto, M.; Fleury, R.; García-Rigo, A.; Hamel, P.; Hartmann, R.; Hernandez-Pajares, M.; et al. Ionospheric Effects on GNSS Performance. In Proceedings of the 2012 6th ESA Workshop on Satellite Navigation Technologies (Navitec 2012) and European Workshop on GNSS Signals and Signal Processing, Noordwijk, The Netherlands, 5-7 December 2012; pp. 1-8.

14. Misra, P.; Enge, P. Global Positioning System: Signals, Measurements, and Performance; Ganga-Jamuna Press: Lincoln, MA, USA, 2006.

15. De Gasperin, F.; Mevius, M.; Rafferty, D.A.; Intema, H.T.; Fallows, R.A. The effect of the ionosphere on ultra-low-frequency radio-interferometric observations. Astron. Astrophys. 2018, 615. [CrossRef]

16. Fallows, R.; Forte, B.; Astin, I.; Allbrook, T.; Arnold, A.; Dorrian, G.; Mevius, M.; Rothkaehl, H.; Matyjasiak, B.; Krankowski, A.; et al. A LOFAR Observation of Ionospheric Scintillation from Two Simultaneous Travelling Ionospheric Disturbances. J. Space Weather. Space Clim. 2020, 10, 1-16.

17. Tiwari, R.; Strangeways, H.J.; Tiwari, S.; Ahmed, A. Investigation of ionospheric irregularities and scintillation using TEC at high latitude. Adv. Space Res. 2013, 52, 1111-1124. [CrossRef]

18. Cherniak, I.; Krankowski, A.; Zakharenkova, I. Observation of the ionospheric irregularities over the Northern Hemisphere: Methodology and service. Radio Sci. 2014, 49, 653-662. [CrossRef]

19. Cherniak, I.; Krankowski, A.; Zakharenkova, I. ROTI Maps: A new IGS ionospheric product characterizing the ionospheric irregularities occurrence. Gps Solut. 2018, 22, 69. [CrossRef]

20. Cherniak, I.; Zakharenkova, I. New advantages of the combined GPS and GLONASS observations for high-latitude ionospheric irregularities monitoring: Case study of June 2015 geomagnetic storm. Earth Planets Space 2017, 69, 66. [CrossRef]

21. Jacobsen, K.S.; Andalsvik, Y.L. Overview of the 2015 St. Patrick's day storm and its consequences for RTK and PPP positioning in Norway. J. Space Weather. Space Clim. 2016, 6, A9. [CrossRef]

22. Prikryl, P.; Ghoddousi-Fard, R.; Weygand, J.; Viljanen, A.; Connors, M.; Danskin, D.; Jayachandran, P.T.; Jacobsen, K.; Andalsvik, Y.; Thomas, E.; et al. GPS phase scintillation at high latitudes during the geomagnetic storm of 17-18 March 2015. J. Geophys. Res. Space Phys. 2016, 121. [CrossRef]

23. Zakharenkova, I.; Cherniak, I.; Krankowski, A. Features of storm-induced ionospheric irregularities from ground-based and spaceborne GPS observations during the 2015 St. Patrick's Day Storm. J. Geophys. Res. Space Phys. 2019, 124, 10728-10748. [CrossRef]

24. Cherniak, I.; Zakharenkova, I.; Sokolovsky, S. Multi-instrumental observation of storm-induced ionospheric plasma bubbles at equatorial and middle latitudes. J. Geophys. Res. Space Phys. 2019, 124, 1491-1508. [CrossRef]

25. Alfonsi, L.; Spogli, L.; Tong, J.; De Franceschi, G.; Romano, V.; Bourdillon, A.; Le, H.; Mitchell, C. GPS scintillation and TEC gradients at equatorial latitudes in April 2006. Adv. Space Res. 2011, 47, 1750-1757. [CrossRef]

26. Yang, Z.; Liu, Z. Low-latitude ionospheric density irregularities and associated scintillations investigated by combining COSMIC RO and ground-based Global Positioning System observations over a solar active period. J. Geophys. Res. Space Phys. 2018, 123, 3998-4014. [CrossRef]

27. Sripathi, S.; Kakad, B.; Bhattacharyya, A. Study of equinoctial asymmetry in the Equatorial Spread F (ESF) irregularities over Indian region using multi-instrument observations in the descending phase of solar cycle 23. J. Geophys. Res. 2011, 116, A11302. [CrossRef]

28. Blewitt, G. An Automatic Editing Algorithm for GPS data. Geophys. Res. Lett. 1990, 17, 199-202. [CrossRef]

29. Hofmann-Wellenhof, B.; Lichtenegger, H.; Collins, J. Global Positioning System. Theory and Practice; Springer: Berlin/Heidelberg, Germany, 2001.

30. Jacobsen, K.S. The impact of different sampling rates and calculation time intervals on ROTI values. J. Spacea Weather. Space Clim. 2014, 4. [CrossRef]

31. Davis, T.N.; Sugiura, M. Auroral electrojet activity index AE and its universal time variation. J. Geophys. Res. 1966, 71, 785-801. [CrossRef]

32. Bilitza, D.; Altadill, D.; Zhang, Y.; Mertens, C.; Truhlik, V.; Richards, P.; McKinnell L.; Reinisch B. The International Reference Ionosphere 2012-A model of international collaboration. J. Space Weather. Space Clim. 2014, 4, A07. [CrossRef]

33. Zhang, X.; Paxton, L.J. An empirical Kp-dependent global auroral model based on TIMED/GUVI FUV data. J. Atmos. Sol. Terr. Phys. 2008, 70, 1231-1242. [CrossRef] 
34. Zhang, Y.; Paxton, L.J.; Bilitza, D.; Doe, R. Near real-time assimilation in IRI of auroral peak E-region density and equatorward boundary. Adv. Space Res. 2010, 46, 8. [CrossRef]

35. Akosofu, S.-I. The Auroral Oval, the Auroral Substorm and Their Relations with the Internal Structure of the Magnetosphere. Planet. Space Sci. 1966, 14, 587-595. [CrossRef]

36. Newell, P.T.; Sotirelis, T.; Wing, S. Diffuse, monoenergetic, and broadband aurora: The global precipitation budget. J. Geophys. Res. 2009, 114, A09207. [CrossRef]

37. Cherniak, I.; Zakharenkova, I.; Krankowski, A. Approaches for Modeling Ionosphere Irregularities Based on the TEC Rate Index. Earth Planets Space 2014, 66, 1-5. [CrossRef]

38. Feldstein, Y.I. Auroral oval. J. Geophys. Res. 1973, 78, 1210-1213. [CrossRef]

39. Newell, P.T.; Liou, K.; Zhang, Y.; Sotirelis, T.; Paxton, L.J.; Mitchell, E.J. OVATION Prime-2013: Extension of auroral precipitation model to higher disturbance levels. Space Weather 2014, 12, 368-379. [CrossRef]

40. Prikryl, P.; Jayachandran, P.T.; Chadwick, R.; Kelly, T. Climatology of GPS phase scintillation at northern high latitudes for the period from 2008 to 2013. Ann. Geophys. 2015, 33, 531-545. [CrossRef]

41. Kintner, P.M., Jr.; Humphreys, T.E.; Hinks, J. GNSS and Ionospheric Scintillation How to Survive the Next Solar Maximum. InsideGNSS 2009, 4, 22-30.

42. Cherniak, I.; Zakharenkova, I. Dependence of the high-latitude plasma irregularities on the auroral activity indices: A case study of 17 March 2015 geomagnetic storm. Earth Planets Space 2015, 67, 151. [CrossRef]

43. Liu, Y.; Fu, L.; Wang, J.; Zhang, C. Studying Ionosphere Responses to a Geomagnetic Storm in June 2015 with Multi-Constellation Observations. Remote Sens. 2018, 10, 666. [CrossRef]

(C) 2019 by the authors. Licensee MDPI, Basel, Switzerland. This article is an open access article distributed under the terms and conditions of the Creative Commons Attribution (CC BY) license (http:/ / creativecommons.org/licenses/by/4.0/). 